\title{
Educação do Campo e formação de professores
}

\author{
Gustavo Cunha de Araújo ${ }^{1}$, Cícero d a Silva ${ }^{2}$ \\ ${ }^{1}$ Universidade Federal do Tocantins - UFT. Departamento de Educação do Campo. Avenida Nossa Senhora de Fátima, 1588, \\ Centro. Tocantinópolis, Brasil. rbec@uft.edu.br. ${ }^{2}$ Universidade Federal do Tocantins - UFT. \\ Autor para correspondência/Author for correspondence: rbec@uft.edu.br
}

A Revista Brasileira de Educação do Campo - RBEC, ISSN 2525-4863, periódico do curso de Educação do Campo, da Universidade Federal do Tocantins, campus de Tocantinópolis, lança o seu terceiro número do volume 3 , referente ao terceiro trimestre de 2018. Este número traz 16 artigos, aprovados dentre os manuscritos recebidos ao longo dos anos de 2017 e 2018.

Neste ano de 2018, buscando aumentar a qualidade nos processos editoriais, bem como nas indexações e artigos publicados na revista, tivemos uma significativa conquista: a revista foi aceita para ser indexada na Emergin Sources Citation Index, coleção da base de dados Clarivate Analytics (Web of Science). É uma base extremamente importante, pois através dela, a revista terá maior visibilidade internacional e será avaliada para integrar outras bases dessa coleção (Web of Science), para que assim a Clarivate Analytics possa nos conceder o fator de impacto.

Neste número, publicamos um artigo especial da autora Luisa Isabel Rodríguez Bello (Universidad Pedagógica Experimental Libertador - Venezuela) intitulado Arquitectura do pathos en "Los dos príncipes" de José Martí que discute um poema literário de José Martí, que, dentre outros assuntos, aborda o campo e as suas simbologias pelo viés literário.

No artigo, Alimentación escolar y promoción del desarrollo: perspectivas en Santa Lucía, de Patrícia Andrade de Oliveira e Silva (Universidade Federal de Uberlândia UFU), a autora destaca os programas de alimentação escolar que contribuem para a formação de estudantes e comunidades em áreas rurais de Santa Lúcia. Dentre alguns resultados encontrados, a autora ressalta a melhora da participação dos alunos na escola e o fortalecimento da gestão escolar.

$\mathrm{Na}$ sequência, o artigo intitulado $O$ educar-se no campo: caneta, enxada e botânica camponesa, de Matias Köhler, Estela Santos, Cristiane Giaretta, Gilmar Gomes e Sebastião Pinheiro (Universidade Federal do Rio Grande do Sul - UFRGS), discute a experiência desenvolvida no projeto sobre botânica camponesa realizada em um assentamento, localizado em Viamão, Rio Grande do Sul. Dentre alguns resultados encontrados pelos pesquisadores, afirmam que os encontros ocorridos ao longo desse projeto com os participantes do assentamento contribuíram com o reconhecimento e o fortalecimento da identidade de resistência no Grupo.

O próximo artigo, A função social da escola do campo e os princípios filosóficos da educação para o MST: um olhar sobre a Escola José Maria, de Francieli Fabris (Instituto Federal do Paraná - IFPR) e Luci Teresinha Marchiori dos Santos Bernardi (Universidade Comunitária da Região de Chapecó - UNOCHAPECÓ), as autoras apresentam

\begin{tabular}{|l|l|l|l|l|l|l|l|} 
Rev. Bras. Educ. Camp. & Tocantinópolis & v. 3 & n. 3 & p. i-iv & set./dez. & 2018 & ISSN: 2525-4863 \\
\hline
\end{tabular}


uma pesquisa que problematiza a função social da escola do campo em assentamentos de reforma agrária na região sul do país. A partir de um estudo de caso, as pesquisadoras descobriram que na escola do campo pesquisada é importante que o processo pedagógico dela seja uma das ferramentas que essa instituição possa fomentar novas opiniões acerca de questões emergentes colocadas na sociedade atual, principalmente relacionadas ao contexto local e aos estudantes camponeses, uma vez que o MST foi fundamental para a criação dessa escola.

Em Base de profissionalidade do trabalho docente na Educação do Campo, de autoria de Wiama de Jesus Freitas Lopes (Universidade Federal de Campina Grande - UFCG) e Emanuela Alves da Silva (Universidade Federal do Rio Grande do Norte - UFRN), os pesquisadores objetivaram compreender a profissionalidade docente de professores do campo, a partir de uma pesquisa bibliográfica. Dentre alguns resultados alcançados nesta investigação, os autores afirmam que é necessário e importante ter uma reorganização curricular contextualizada com as demandas e interesses dos sujeitos do campo.

Já no artigo Education of teachers from rural schools: Notes on some actions and Programs Developed by Higher Education federal schools in Minas Gerais State, de autoria dos pesquisadores Rita Laura Avelino Cavalcante, Júlia Loren dos Santos e José Elenito Teixeira Morais (Universidade Federal de São João del-Rei - UFSJ), são discutidos algumas ações e alguns programas oferecidos pelas instituições federais de ensino superior do estado de Minas Gerais relacionados à formação de professores do campo. Os autores chegaram a alguns resultados que indicam uma expansão de cursos voltados a esse tipo de formação, porém, essa expansão não deixou clara a consolidação de uma política pública voltada à formação de professores do campo no estado de Minas Gerais, uma vez que essas ações ainda não superaram a descontinuidade das políticas públicas predominantes nas últimas décadas.

Em seguida, Por uma Ciência popular da vida: ancestralidade e Agroecologia na formulação das Ciências da Natureza da Educação do Campo, Marcelo de Albuquerque Vaz Pupo (Universidade Federal do Pampa - UNIPAMPA) discute aspectos históricos e conceituais acerca da Ciência da Natureza da Educação do Campo. Na pesquisa realizada, o autor ressalta um ensino de Ciências para a Educação do Campo, que faz da Agroecologia e dos modos de apropriação dos agroecossistemas elementos centrais de análise e orientação pedagógica.

Posteriormente, no artigo intitulado Licentiate Degree in Rural Education: contributions to training monitors of Agricultural Family Schools, de Diego Gonzaga Duarte da Silva e Lourdes Helena da Silva (Universidade Federal de Viçosa - UFV), os autores analisam as avaliações dos monitores de Escolas Família Agrícolas - EFA sobre as contribuições do curso de Licenciatura em Educação do Campo da UFV para com as práticas pedagógicas desenvolvidas nessas escolas. Segundo os autores, os resultados indicam que a LEDOC tem sim contribuído para a formação dos monitores tanto pela apropriação dos saberes didático-pedagógicos quanto pelo estímulo à realização de práticas interdisciplinares.

$\mathrm{Na}$ sequência, em Escolas com classes multisseriadas no município de Santa Maria de Jetibá-ES: memórias na mediação fotográfica, de autoria de Juber Helena Baldotto Delboni e Gerda Margit Schütz Foerste (Universidade Federal do Espírito Santo UFES), objetiva-se compreender os processos de constituição das escolas multisseriadas e os sentidos que lhes são atribuídos junto às comunidades do campo. As pesquisadoras compreendem que é importante situar o debate para além da concepção equivocada de que as escolas multisseriadas são espaços de atraso ou de "anomalia" no sistema educacional. Para elas, essas escolas são espaços vivos de produção da vida, que dialogam com culturas e saberes de agricultores familiares das comunidades do campo.

No artigo Who Sits at the Table? A female farm activist's experience during the

\begin{tabular}{|l|l|l|l|l|l|l|l|}
\hline Rev. Bras. Educ. Camp. & Tocantinópolis & v. 3 & n. 3 & p. i-iv & set./dez. & 2018 & ISSN: 2525-4863 \\
\hline
\end{tabular}


De Doorns farm workers strike, South Africa, de Kara Grace Mackay (University of Pretoria, África do Sul), a autora discute o ativismo de uma líder rural na greve dos fazendeiros conhecida como De Doorns, entre os anos de 2012 a 2013 na África do Sul. Por meio de uma pesquisa etnográfica, a autora afirma que houve perdas e ganhos entre os trabalhadores agrícolas durante e após essa greve (como o aumento das desigualdades sociais), o que reforça a necessidade de igualdade e justiça social para essa população camponesa que luta por seus direitos.

No texto Histórias de vida tramadas aos processos formativos de uma professora de escola do campo do município de Restinga Sêca/RS, de autoria de Mariane Bolzan e Helenise Sangoi Antunes (Universidade Federal de Santa Maria - UFSM), as autoras discutem alfabetização e Educação do Campo numa escola localizada em Restinga Sêca, no Rio Grande do Sul. As pesquisadoras compreendem na pesquisa realizada que é importante para o professor alfabetizador que atua em escolas do campo ter melhor visibilidade e valorização diante do trabalho que exerce nessas escolas, pois isso é relevante para o debate sobre os processos de formação nessas instituições que envolvem a alfabetização da população campesina.

O próximo artigo, Interfaces entre a Educação do Campo e o êxodo rural da juventude camponesa, de Marizete Andrade da Silva (Universidade Federal de Minas Gerais - UFMG), a partir de uma pesquisa bibliográfica, a autora compreende que o fenômeno do êxodo rural da juventude camponesa provém de inúmeros fatores, em que sobressai a ausência de políticas públicas abrangentes. Na pesquisa realizada, a autora ressalta também a realidade objetiva das populações que criam e recriam o espaço do campo como modo de vida.

Em Projetos educacionais como metodologia de ensino na escola de Educação do Campo Sol Nascente de Confresa-MT, de Noemia de Souza Ventura e Marcelo Franco Leão (Instituto Federal de Mato Grosso - IFMT), os autores objetivam mostrar a necessidade de desenvolver metodologias de ensino voltadas para a Educação do Campo, analisando o desenvolvimento de projetos educacionais voltados a escolas do campo. No estudo em questão, os autores afirmam que é importante inserir a leitura de livros literários como ação dentro desses projetos, uma vez que pode contribuir significativamente para a aprendizagem dos estudantes.

No próximo manuscrito, Ciências da Natureza e materialismo histórico-dialético: encontros e desencontros na formação de educadores do campo, de Emilio Romanini Netto (Universidade Federal do Paraná - UFPR), o autor busca verificar encontros e desencontros do enlace entre a Ciências da Natureza e o materialismo histórico-dialético, ao relacionar com o projeto de formação de educadores do campo. A partir de alguns resultados encontrados, o pesquisador compreende que o materialismo histórico-dialético é capaz de fundamentar novas análises sobre a realidade natural. Contudo, o autor entende que a disputa de concepção entre os sujeitos envolvidos na execução do projeto de Educação do Campo e os formatos disciplinares dos cursos de Pedagogia e Licenciatura são desconectados, uma vez que os conteúdos dos materiais didáticos das Ciências da Natureza não se relacionam a uma perspectiva co-evolutiva ou histórico-natural.

No trabalho A aprendizagem da docência de acadêmicas em formação inicial: novas temporalidades, de Ana Cláudia da Silva Rodrigues, Rayane Pereira Santos e Adriege Matias Rodrigues (Universidade Federal da Paraíba - UFPB), a partir de um projeto de extensão desenvolvido em escolas do campo da Paraíba, as pesquisadoras objetivaram compreender como ocorre a aprendizagem da docência de acadêmicas a partir das ações desenvolvidas nesse projeto. Segundo as autoras, os resultados indicaram que a aprendizagem da docência não se concretiza sem a articulação dos diferentes espaços formativos da prática pedagógica a partir de novas temporalidades.

\begin{tabular}{|l|l|l|l|l|l|l|l|}
\hline Rev. Bras. Educ. Camp. & Tocantinópolis & v. 3 & n. 3 & p. i-iv & set./dez. & 2018 & ISSN: 2525-4863 \\
\hline
\end{tabular} 
Em seguida, o artigo Formação de professores quilombolas e o Programa Etnomatemática: repensando processos de ensino da Matemática, de autoria de Érika Lúcia Ferreira de Jesus e Roberto Barcelos Souza (Universidade Estadual de Goiás - UEG), apresenta uma pesquisa desenvolvida no estado de Goiás com estudantes quilombolas. Nessa investigação, os autores afirmam que, para promover o reconhecimento de ações metodológicas para o ensino de Matemática que vise combater às diferenças, a desigualdade e a discriminação e quem sabe vislumbrar a verdadeira equidade nas relações socioculturais, é importante e necessário investir na formação de professores.

Por último, em Educação do Campo: uma proposta de formação de professores para classes multisseriadas em formato de roda, de autoria de Flaviana Maria de Oliveira e Roberto Gimenez (Universidade Cidade de São Paulo - UNICID), os autores apresentam uma pesquisa de mestrado realizada em São Paulo cujo objetivo foi investigar a Educação do Campo e a pluralidade existente no contexto escolar, apresentando como produto de intervenção uma proposta de formação continuada em formato de roda de conversa. $\mathrm{Na}$ pesquisa desenvolvida, os autores compreenderam que a roda de conversa como proposta para formação docente possibilita aprender a registrar o planejamento e a ação dos procedimentos da roda e a elaboração de diário, o que pode ser considerado salutar para o desenvolvimento de propostas associadas às demandas de inclusão típicas de escolas do campo.

Com a publicação desta edição, a qual traz uma grande diversidade de artigos oriundos de diferentes instituições brasileiras e estrangeiras, a RBEC encerra o ano de 2018 ainda mais forte. Evidentemente, isso é fruto do trabalho sério da equipe editorial e da confiança que os diferentes autores depositam nesse periódico para publicar os resultados de suas pesquisas. Portanto, com o crescimento da RBEC a Educação do Campo ganha maior visibilidade e espaço na sociedade em geral, corroborando a missão dessa revista.

Desejamos a todos e a todas boas leituras e um próspero ano de 2019!

Informações do Editorial / Editorial Information

Conflitos de interesse: Os editores declararam não haver nenhum conflito de interesse referente a este Editorial.

Conflict of Interest: None reported.

Orcid

Gustavo Cunha de Araújo

(iD)

https://orcid.org/0000-0002-1996-5959

Cícero da Silva

https://orcid.org/0000-0001-6071-6711

Como citar este Editorial / How to cite this Editorial

APA

Araújo, G. C., \& Silva, C. (2018). Educação do Campo e formação de professores. Rev. Bras. Educ. Camp., 3(3), i-iv. DOI: http://dx.doi.org/10.20873/uft.2525-4863.2018v3n3pi

ABNT

ARAÚJO, G. C.; SILVA, C. Educação do Campo e formação de professores. Rev. Bras. Educ. Camp., Tocantinópolis, v. 3, n. 3 , set./dez., p. i-iv, 2018. DOI: http://dx.doi.org/10.20873/uft.2525-4863.2018v3n3pi 